\title{
Spatial patterns of mitochondrial and nuclear gene pools in chamois (Rupicapra r. rupicapra) from the Eastern Alps
}

\author{
H Schaschl, D Kaulfus, S Hammer ${ }^{1}$ and F Suchentrunk \\ Research Institute of Wildlife Ecology, Veterinary Medicine University of Vienna, Savoyenstrasse 1, A-1160 Vienna, Austria
}

\begin{abstract}
We have assessed the variability of maternally (mtDNA) and biparentally (allozymes) inherited genes of 443 chamois (Rupicapra r. rupicapra) from 19 regional samples in the Eastern Alps, to estimate the degree and patterns of spatial gene pool differentiation, and their possible causes. Based on a total mtDNA-RFLP approach with 16 hexanucleotiderecognizing restriction endonucleases, we found marked substructuring of the maternal gene pool into four phylogeographic groups. A hierarchical AMOVA revealed that $67.09 \%$ of the variance was partitioned among these four mtDNAphylogroups, whereas only $8.04 \%$ were because of partitioning among regional samples within the populations, and $24.86 \%$ due to partitioning among individuals within regional samples. We interpreted this spatial pattern of mtDNA
\end{abstract}

variability as a result of immigration of chamois from different Pleistocene refugia surrounding the Alps after the withdrawal of glaciers, rather than from topographic barriers to gene flow, such as Alpine valleys, extended glaciers or woodlands. However, this striking geographical structuring of the maternal genome was not paralleled by allelic variation at 33 allozyme loci, which were used as nuclear DNA markers. Wright's hierarchical F-statistics revealed that only $\leqslant 0.45 \%$ of the explained allozymic diversity was because of partitioning among the four mtDNA-phylogroups. We conclude that this discordance of spatial patterns of nuclear and mtDNA gene pools results from a phylogeographic background and sexspecific dispersal, with higher levels of philopatry in females. Heredity (2003) 91, 125-135. doi:10.1038/sj.hdy.6800290

Keywords: mtDNA; RFLP; allozymes; population structure; chamois; Rupicapra rupicapra

\section{Introduction}

Chamois (Rupicapra spp.) are group-living ungulates that preferentially inhabit alpine pastures and rocky areas in diverse mountain regions of Europe and the Middle East. Several morphological characteristics place chamois somewhat separate from most of the other fossil or extant forms of the Rupicaprini, and fossil remains suggest an origin of chamois in eastern Europe or southwest Asia (Lovari, 1987). Two species of chamois are considered to occur in Europe, Rupicapra rupicapra and $R$. pyrenaica (Masini and Lovari, 1988). While Pyrenean chamois (R. pyrenaica) are disjunctly distributed in southwest Europe (Pyrenees, Cantabrian Mountains) and the southern Apennine mountain range in Italy (Shackleton and the IUCN/SSC Caprinae Specialist group, 1997), native populations of $R$. rupicapra roam the Alps, the Tatra massif (Slovak Republic), the Carpathian mountains (Romania), and various mountain massifs in the Balkans, Asia Minor, and the Caucasus (eg, Lovari, 1987). Within the Alps, chamois are more or less continuously distributed in higher altitudes, and two subspecies have been described: Rupicapra r. rupicapra, ranging over most of the Alpine regions, and R. r. carthusiana, from the

Correspondence: H Schaschl. Institute of Zoology, ZLS, Regent's Park, London NW1 4RY, UK. E-mail: Helmut.Schaschl@ioz.ac.uk

${ }^{1}$ Current address: AG General Genetics, Institute of Medical Biology, Waehringerstrasse 10, A-1090 Vienna, Austria.

Received 12 June 2002; accepted 12 February 2003
Chartreuse massif in the French Alps (Shackleton and the IUCN/SSC Caprinae Specialist group, 1997). Gene pool divergence between these two subspecies as assessed by multilocus allozyme electrophoresis is apparently higher than among local populations of $R$. r. rupricapra (Pemberton et al, 1989), and allozyme studies also indicate somewhat reduced gene flow among several regional populations of chamois from the Eastern Alps (Miller and Hartl, 1986). Here, we study the degree of gene pool substructuring of chamois from the Eastern Alps. Most parts of this region were covered by a $2000-3000 \mathrm{~m}$ thick ice sheet during long periods of the late Pleistocene, and deglaciation started only c. 15-12 kyr BP (Van Husen, 1987). Obviously, post-Pleistocene spread of many tree species into central Europe occurred within a few millennia of the end of the Pleistocene and at the beginning of the Holocene, which led to rapid reforestation of Alpine valleys and basins after the retreat of the glaciers (Lang, 1994; Taberlet et al, 1998). These environmental changes likely provided only a short period of time for colonization of the Alps by chamois, since chamois prefer rocky, unwooded terrain rather than extended woodlands, where large predators, such as wolf, lynx, and bear are present. Fossil evidence (eg Döppes, 1997; Galik, 1997) indicates that chamois were roaming central Europe during late-glacial times. Colonization of the present range of chamois in the Eastern Alps might have resulted from only one major cohesive population or several isolated late-Pleistocene source populations with more or less distinctly differentiated 
gene pools. In addition to different colonization routes along mountain ranges, drift effects in pioneer populations (founder effects) and later on during possibly dramatic population crashes caused by sarcoptic mange epidemics (see Rossi et al, 1995) might have produced a distinct substructuring of the extant gene pool in the study region. In this study, we examine the hypothesis of distinct phylogeographic structuring in chamois from the Eastern Alps as a consequence of postglacial immigration from different refugia by using an RFLP approach to the total mtDNA. However, the maternally inherited mitochondrial DNA (mtDNA) might overemphasize a possible phylogeographic structuring, because of the higher level of philopatry in female chamois as compared to males (Loison et al, 1999). Therefore, we use a multilocus allozyme approach to test for increased gene flow among populations in the nuclear DNA, and expect less geographical structuring with this marker system.

\section{Materials and methods}

\section{Study regions and sampling}

Liver and kidney samples of 443 chamois (R. r. rupicapra) from 19 populations from different mountain ranges in the Eastern Alps (Figure 1) were collected during regular hunts in several provinces of Austria (Carinthia, Lower Austria, Salzburg, Styria, Upper Austria), Germany (Berchtesgaden Nationalpark), Slovenia (Kamnik region), and northern Italy (South Tyrol, Texel-Gruppe). All samples were taken immediately after death and frozen at $-20^{\circ} \mathrm{C}$, normally within $12 \mathrm{~h}$.

\section{mtDNA-RFLP analysis}

mtDNA of 308 chamois was isolated from liver cells following the procedures as described in Hartl et al (1993). RFLP analysis was carried out by digesting the entire mtDNA with 16 hexanucleotide-recognizing type II restriction endonucleases (from Roche). The mtDNA fragments obtained were separated electrophoretically and then visualized under UV light according to Hammer et al (1995). The DNA-markers Lambda phage DNA digested with HindIII and Lambda phage DNA digested with a combination of HindIII and EcoRI served as size standards and were applied to determine the fragment lengths of the restriction segments. Furthermore, we assumed that the length of the entire mtDNA of chamois was approximately the same as the mtDNA genome of cattle, which consists of 16340 nucleotides

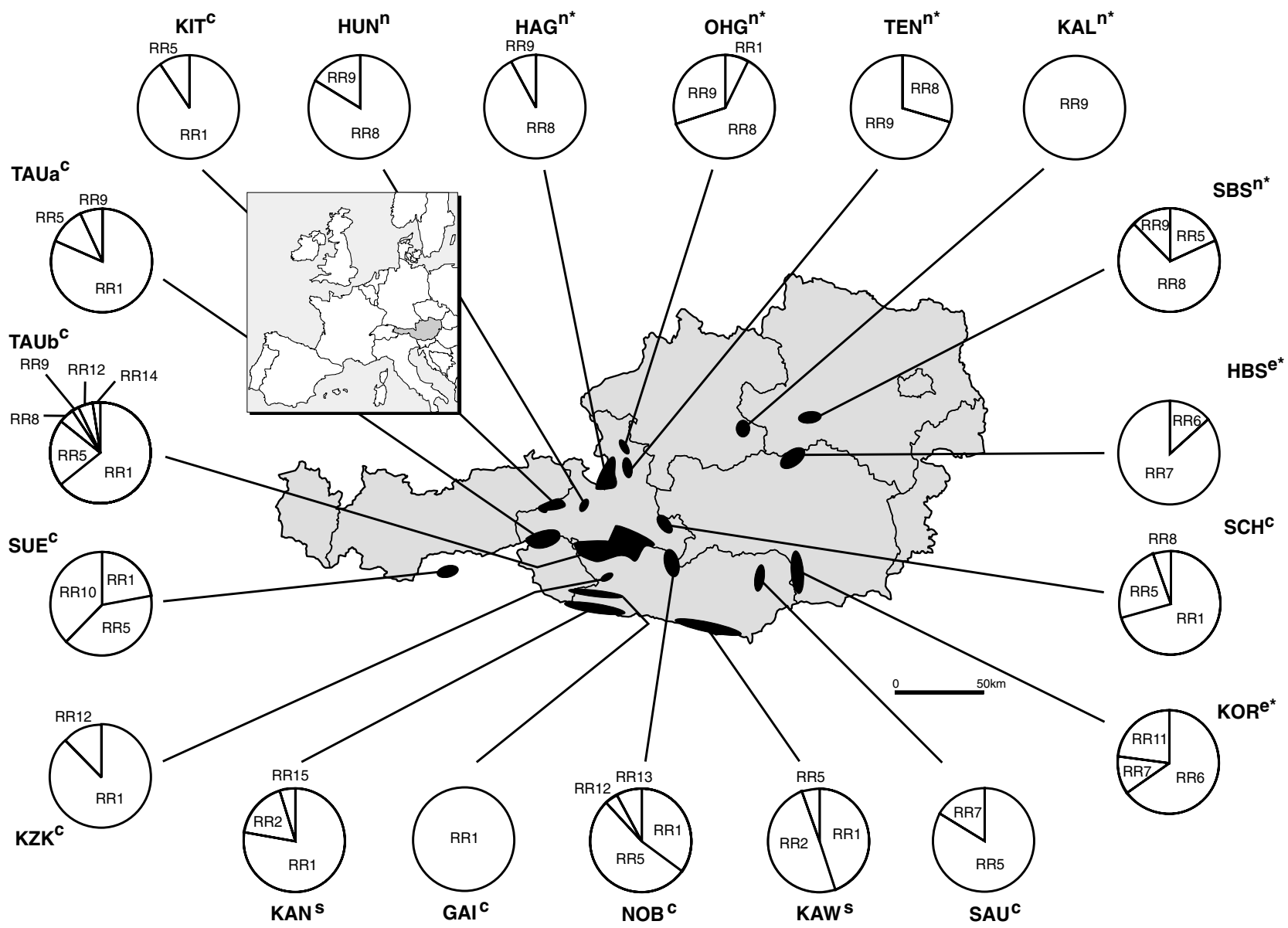

Figure 1 Study region in the Eastern Alps showing the 19 populations of chamois. The location of the Eastern Alps within Europe is given in the inset. For acronyms of populations, see Table 1. Frequency distribution of mtDNA haplotypes (RR1-RR15) is given for each population. Lower case letters attached to acronyms allocate single populations to one of the four distinct mtDNA-phylogroups found in this study: $\mathrm{c}=$ 'Central mtDNA-phylogroup', $\mathrm{e}=$ 'Eastern mtDNA-phylogroup', $\mathrm{n}=$ 'Northern mtDNA-phylogroup', $\mathrm{s}=$ 'Southern mtDNA-phylogroup'. Asterisks attached to upper case letters denote geographically marginal populations within the distribution range of chamois. 
(Anderson et al, 1982). Fragment lengths shorter than 200 basepairs (bp) could not be detected by UV visualization. Haplotypes were defined based on the composition of restriction band patterns, and labelled with 'RR' ( $R$. rupicapra) and a serial number. RR1, RR2, RR5, and RR6 detected in this study were previously found by Hammer et al (1995) in the Alpine chamois (haplotypes 7 and 8 of Hammer et al (1995), however, were haplotypes of Pyrenean chamois, different from 'RR7' and 'RR8' of our study).

\section{Statistical treatment of mtDNA-RFLP data}

Based on the presence or absence of restriction sites, pairwise genetic distances between haplotypes were calculated after Nei and Li (1979). Phylogenetic relationships among haplotypes were inferred by constructing a splits graph (Bandelt and Dress, 1992) with the SplitsTree program (Huson, 1998). Genetic diversity was summarized as haplotype diversity and nucleotide diversity within populations, and nucleotide divergence among populations, calculated as net nucleotide diversity by the method of Nei (1987) using the REAP software package (McElroy et al, 1992). According to a KolmogorovSmirnov test, arcsin square root-transformed nucleotide diversity values of populations were normally distributed. They were used to perform an ANCOVA (general linear model; SPSS 8.0) to check for variation between populations from central parts of the study region as compared to those from the margins of the range of chamois in the Eastern Alps and controlling for unbalanced sample sizes. Marginal populations might harbour less mtDNA diversity because of gene flow only via certain routes into marginal ranges. Partitioning of mtDNA variation within and among populations was examined with AMOVA (Excoffier et al, 1992) using the software package ARLEQUIN version 1.1 of Schneider et al (1996). In a separate approach, we performed a hierarchical AMOVA with populations grouped into four large regions. We established these regions on the basis of the pronounced spatial distribution of haplotypes (see Results). Significances of $\phi_{\mathrm{ST}}$-statistics were tested using a permutation procedure with 1000 randomizations. For testing the relation between relative genetic and geographic distance among the 19 populations, we compared pairwise linearized transformed $\phi_{\mathrm{ST}_{\mathrm{T}}}$-values $\left(\phi_{\mathrm{ST}} /\right.$ $1-\phi_{\mathrm{ST}}$; Rousset, 1997) with the respective Euclidean geographical distance in kilometers. The linearization of the $\phi_{\mathrm{ST}}$-values was based on the stepping stone model by Rousset (1997). The significance level of concordance of the two matrices was computed using a Mantel (1967) test. To estimate the phylogenetic relationships among the 19 populations, pairwise net nucleotide diversity values were used to generate a neighbour joining dendrogram with the PHYLIP package (Felsenstein, 1993).

\section{Allozyme analysis}

Kidney samples of 443 chamois were used in horizontal starch gel electrophoresis with enzyme-specific staining to resolve allelic variation of 21 isozyme systems, corresponding to 33 putative structural gene loci. In tissue preparation, electrophoresis, and biochemicalgenetic staining, we followed Hartl and Höger (1986), and Grillitsch et al (1992). For resolving allelic variants, direct side-by-side comparisons of migrating allozymes were carried out including marker samples on all gels. Interpretation of band patterns in terms of allelic variation was based on the principles outlined in Harris and Hopkinson (1976), and Rothe (1994). In numbering isozymes and designation of alleles we followed Miller and Hartl (1986). The following enzyme systems were screened (abbreviation, EC number of enzymes, and corresponding loci scored in parentheses): $\alpha$-glycerophosphate dehydrogenase (GDC, 1.1.1.8, Gdc), sorbitol dehydrogenase (SDH, 1.1.1.14, Sdh), lactate dehydrogenase (LDH, 1.1.1.27, Ldh-1,-2), malate dehydrogenase (MOR, 1.1.1.37, Mor-1,-2), malic enzyme (MOD, 1.1.1.40, Mod-1,-2), isocitrate dehydrogenase (IDH, 1.1.1.42, Idh-1,-2), 6-phosphogluconate dehydrogenase, (PGD, 1.1.1.44, Pgd), glucose dehydrogenase (GDH, 1.1.1.47, Gdh), glucose-6-phosphate dehydrogenase (G6PD, 1.1.1.49, Gpd), superoxide dismutase (SOD, 1.15.1.1, Sod-1,-2), aspartate aminotransferase (AAT, 2.6.1.1, Aat-1,-2), hexokinase (HK, 2.7.1.1, Hk-1), creatine kinase (CK, 2.7.3.2, Ck-1,-2), adenylate kinase (AK, 2.7.4.3, Ak-1,-2), phosphoglucomutase (PGM, 2.7.5.1, Pgm-1-2) esterases (ES, 3.1.1.1, Es-1,-2; 4.2.1.1, Es-d), acid phosphatase (ACP, 3.1.3.2, Acp-1,-2), aminoacylase (ACY, 3.5.1.14, Acy), aconitase (ACO, 4.2.1.3, Aco), mannose phosphate isomerase (MPI, 5.3.1.8, Mpi), and glucose phosphate isomerase (GPI, 5.3.1.9, Gpi).

\section{Statistical treatment of allozyme data}

We used the BIOSYS-1 package, release 1.7 (Swofford and Selander, 1989) to calculate allele frequencies, average heterozygosity $\left(H_{0}-\right.$ observed, $H_{\mathrm{e}}$ - expected), proportion of polymorphic loci with the $99 \%$ criterion $\left(P_{99 \%}\right)$, mean number of alleles per locus based on all 33 loci $(A)$, as well as for performing Fisher's exact tests of deviations of genotype frequencies from Hardy-Weinberg expectations in populations for calculating Wright's (1978) F-statistic and hierarchical F-statistic, Nei's (1978) $D$ and modified Rogers' genetic distances (Wright, 1978) between pairs of populations, and to construct a Wagner dendrogram of genetic relationships among the populations based on modified Rogers' distances. We tested variation of allele frequencies at the polymorphic loci Pgm-2 and Es-2 among populations by G-tests, with aggregated allele frequencies for the latter locus. We did not perform $G$-tests for the other three loci found to be polymorphic (see Table 3), because of the occurrence of variant alleles with very low frequencies in only one or two populations, respectively. We used the FSTAT program (version 2.9.3; Goudet, 2001) to calculate locus-specific values of 'allelic richness' (Rs), which is based on a rarefaction approach and accounts for unbalanced sample sizes, and calculated populationspecific Rs values as arithmetic means over all polymorphic loci. We hypothesized lower $H_{\mathrm{e}}$ - and Rs values in populations at the margin of the distributional range of chamois in the Eastern Alps as compared to more central parts, because of a lower probability of receiving genes from the limited number of neighbour populations. To test for such differences, we performed an ANCOVA on normally distributed arcsin square roottransformed $H_{\mathrm{e}}$-values of 'marginal' and 'central' populations (see Figure 1) by controlling for sample sizes. In addition, we used the FSTAT program (version 2.9.3; 
Goudet, 2001) to test for significant (1000 permutations) differences of Rs values in 'central' and 'marginal' populations. Correspondence of spatial allozyme, mtDNA, and linear geographical distances among populations was tested by Mantel tests. Significance levels for series of tests were corrected by the sequential Bonferroni procedure (SBP) (Rice, 1989).

\section{Results}

\section{mtDNA-RFLP}

Restriction sites and diversity: Digesting mtDNA with 16 six-base cutting restriction endonucleases yielded a total of 70 restriction sites, which defined 13 different mtDNA haplotypes in 308 chamois from the Eastern Alps (RR1, RR2, RR5-RR15). Phylogenetic relationships between the haplotypes detected, based on Nei and Li's (1979) distances are displayed in a splits graph (Figure 2). RR5 appears to be a central haplotype, surrounded by other haplotypes in a starlike manner. The 13 haplotypes differed at most in six restriction sites that corresponded to a genetic distance range of $0.0013-0.0078$. The number of different haplotypes per population averaged 2.63, with a range of 1-6. The geographic distribution and frequencies of haplotypes are shown in Figure 1. The most frequent haplotypes were RR1 (40.9\%), RR8 (18.2\%), RR5 (14.3\%), and RR9 (10.1\%). While RR1 and RR5 were the most widespread haplotypes, all other haplotypes were more or less confined to certain regions. RR8 and RR9 were restricted to the populations of northern Salzburg (HUN, HAG, TEN, OHG), Upper Austria (KAL), and Lower Austria (SBS), except for some single cases in adjacent study areas (TAUa, TAUb, SCH; Figure 1).

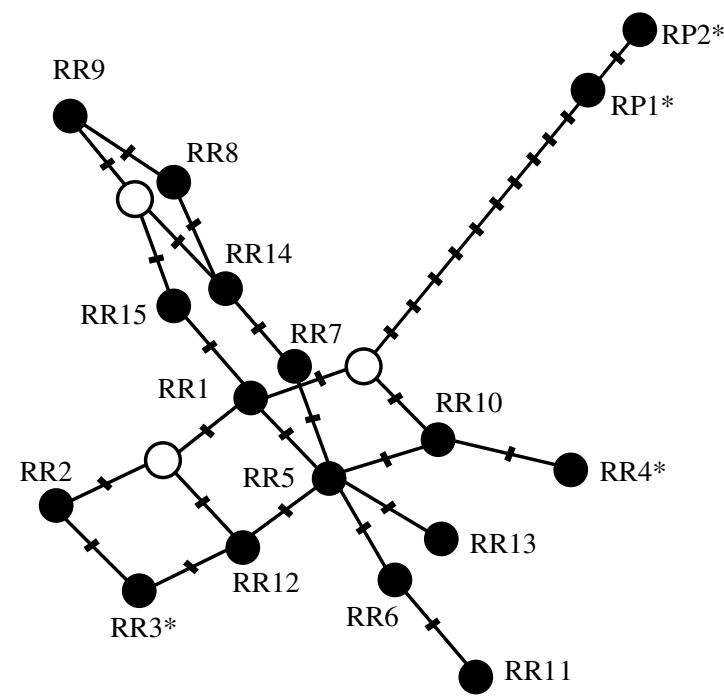

Figure 2 Splits graph based on pairwise genetic distances (Nei and $\mathrm{Li}, 1979)$, representing phylogenetic relationships among the 15 mtDNA haplotypes RR1-RR15 (Alpine chamois, $R$. rupicapra) and RP1 and RP2 (Pyrenean chamois, R. pyrenaica). Black circles represent mtDNA haplotypes found and white circles represent inferred haplotypes. Asterisks denote haplotypes that were found in a previous study by Hammer et al (1995). Restriction site changes are indicated by slashes across network branches.
The haplotype RR7 appeared in only three populations from the eastern part of the study area (SAU, KOR, and HBS), RR6 only in KOR and HBS, and RR11 was found only in the southeastern population KOR. RR2 was limited to KAW and RR10 to South Tyrol (SUE). The remaining haplotypes RR12-RR15 had scattered distributions with overall frequencies ranging between 0.3 and $1.3 \%$. RR3 and RR4 (labelled with * in Figure 2) are haplotypes that were found already in a previous study in Slovenian and Swiss chamois, respectively, by Hammer et al (1995), and were not detected in the present study. However, they could be perfectly integrated into the splits graph (Figure 2).

\section{Variation within and differentiation among populations studied}

Haplotype diversities (Table 1) ranged from 0.000 in KAL and GAI to 0.705 in SUE with an average of $0.3838 \pm 0.00206$. Nucleotide diversities ranged from $0.0000 \%$ in KAL and GAI to $0.1571 \%$ in SBS, with an average of $0.0801 \pm 0.0000$. There was no correlation between sample sizes and nucleotide diversity values $(P>0.05$, Spearman rank correlation test). Table 2 presents a matrix of $\phi_{\mathrm{ST}}$-values for pairwise differentiation between populations where the magnitude of differentiation ranged from -0.00354 to 1.000 . Almost all pairwise values of differentiation were significant at an overall level of $\alpha=0.05$ (Table 2, single significance values are indicated by ${ }^{*}$ ). Remarkably, strong differentiation with values over 0.81 was observed between several pairs of populations with short linear geographical distances and no obvious barriers for migration (compare Figure 1 and Table 2): HBS-KAL (0.91933*), KAL-SCH (0.82979*), OHG-KIT $\left(0.81905^{*}\right)$, TEN-KIT $\left(0.8983^{*}\right)$, TEN-TAUa $\left(0.83457^{*}\right)$, HAG-KIT $\left(0.90435^{*}\right)$, HUN-KIT $\left(0.93811^{*}\right)$, HUN-TAUa $\left(0.85079^{*}\right)$, and HUN-KZK $\left(0.88918^{*}\right)$. The neighbour-joining dendrogram (Figure 3 ), based on the pairwise net nucleotide diversity values, and the spatial distribution of haplotypes indicate grouping of the 19 populations into four mtDNA-phylogroups. The populations SBS, HUN, HAG, OHG, TEN, and KAL constituted the most distinguishable mtDNA-phylogroup, which was defined as 'Northern mtDNA-phylogroup'. In spite of the long geographical distance between KOR and HBS, these two populations were combined to form the 'Eastern mtDNA-phylogroup' because of the common occurrence of the haplotypes RR6 and RR7. Apart from the 'Eastern mtDNA-phylogroup', RR7 is present only in the adjacent population SAU. RR6 is unique to the 'Eastern mtDNA-phylogroup'. The third mtDNA-phylogroup, which was termed 'Southern mtDNA-phylogroup', referred to the populations KAW and KAN. These two populations are characterized by the haplotype RR2 that occurred nowhere else. The 'Central mtDNA-phylogroup' includes the populations KIT, TAUa, TAUb, NOB, SCH, SAU, GAI, KZK, and SUE and is characterized by their common haplotypes RR1 and RR5. The hierarchical AMOVA revealed that $67.09 \%$ $(P<0.00001)$ of the genetic variance was partitioned among these four mtDNA-phylogroups, whereas only $8.04 \%(P<0.00001)$ of the molecular variance was found among populations within the four mtDNA-phylogroups, and $24.86 \%(P<0.00001)$ of the variance was identified within the 19 populations. Subjecting the 
Table 1 Haplotype diversities $(H)$, standard deviations (SD), nucleotide diversities $(\pi)$, sample sizes $(N)$, and haplotype frequencies per population

\begin{tabular}{|c|c|c|c|c|c|c|c|c|c|c|c|c|c|c|c|c|c|c|c|c|}
\hline & & \multicolumn{19}{|c|}{ Populations } \\
\hline & & $H B S$ & SBS & $K A L$ & $\mathrm{OHG}$ & TEN & $H A G$ & HUN & KIT & ТАUа & $T A U b$ & $N O B$ & $\mathrm{SCH}$ & $S A U$ & KOR & $K A W$ & KAN & $G A I$ & $K Z K$ & SUE \\
\hline$H$ & & 0.286 & 0.508 & 0.000 & 0.564 & 0.441 & 0.211 & 0.333 & 0.182 & 0.342 & 0.548 & 0.606 & 0.471 & 0.333 & 0.544 & 0.582 & 0.385 & 0.000 & 0.250 & 0.705 \\
\hline$S D$ & & 0.196 & 0.126 & 0.000 & 0.112 & 0.098 & 0.101 & 0.215 & 0.144 & 0.140 & 0.076 & 0.066 & 0.118 & 0.215 & 0.111 & 0.061 & 0.113 & 0.000 & 0.180 & 0.064 \\
\hline$\pi(\%)$ & & 0.0743 & 0.1571 & 0.0000 & 0.1267 & 0.0574 & 0.0556 & 0.0433 & 0.0236 & 0.0791 & 0.1348 & 0.0904 & 0.1032 & 0.0433 & 0.1071 & 0.1521 & 0.0929 & 0.0000 & 0.0650 & 0.1167 \\
\hline$N$ & & 7 & 16 & 8 & 13 & 17 & 27 & 6 & 11 & 16 & 42 & 26 & 17 & 6 & 17 & 18 & 22 & 18 & 8 & 13 \\
\hline \multirow{13}{*}{$\begin{array}{l}\text { Haplotype } \\
\text { frequency (\%) }\end{array}$} & RR1 & - & - & - & 7.7 & - & 3.7 & - & 90.9 & 81.2 & 64.3 & 34.6 & 70.6 & - & - & 44.4 & 77.3 & 100 & 87.5 & 23.0 \\
\hline & RR2 & - & - & - & - & - & - & - & - & - & - & - & - & - & - & 50.0 & 18.2 & - & - & - \\
\hline & RR5 & - & 18.8 & - & - & - & - & - & 9.1 & 12.5 & 21.4 & 53.8 & 23.5 & 83.3 & - & 5.6 & - & - & - & 38.5 \\
\hline & RR6 & 14.3 & - & - & - & - & - & - & - & - & - & - & - & - & 64.7 & - & - & - & - & - \\
\hline & RR7 & 85.7 & - & - & - & - & - & - & - & - & - & - & - & 16.7 & 11.8 & - & - & - & - & - \\
\hline & RR8 & - & 68.8 & - & 61.5 & 29.4 & 88.9 & 83.3 & - & - & 4.8 & - & 5.9 & - & - & - & - & - & - & - \\
\hline & RR9 & - & 12.5 & 100 & 30.8 & 70.6 & 7.4 & 16.7 & - & 6.3 & 2.4 & - & - & - & - & - & - & - & - & - \\
\hline & RR10 & - & - & - & - & - & - & - & - & - & - & - & - & - & - & - & - & - & - & 38.5 \\
\hline & RR11 & - & - & - & - & - & - & - & - & - & - & - & - & - & 23.5 & - & - & - & - & - \\
\hline & RR12 & - & - & - & - & - & - & - & - & - & 4.8 & 3.9 & - & - & - & - & - & - & 12.5 & - \\
\hline & RR13 & - & - & - & - & - & - & - & - & - & - & 7.7 & - & - & - & - & - & - & - & - \\
\hline & RR14 & - & - & - & - & - & - & - & - & - & 2.4 & - & - & - & - & - & - & - & - & - \\
\hline & RR15 & - & - & - & - & - & - & - & - & - & - & - & - & - & - & - & 4.5 & - & - & - \\
\hline
\end{tabular}

Acronyms of populations and associated geographic names: HBS, Hochschwab; SBS, district Scheibbs; KAL, Kalkalpen; OHG, Osterhorngruppe; TEN, Tennengebirge; HAG, Hagengebirge and Berchtesgaden; HUN, Hundstein; KIT, Kitzbühler Alpen; TAUa, Hohe Tauern (west); TAUb, Hohe Tauern (south-east); NOB, Nockberge and Gurktaler Alpen; SCH, Schladminger Tauern; SAU, Saualpe; KOR, Koralpe; KAW, Karawanken; KAN, Karnische Alpen; GAI, Gailtaler Alpen; KZK, Kreuzeckgruppe; SUE, South Tyrol (Texel-Gruppe). 


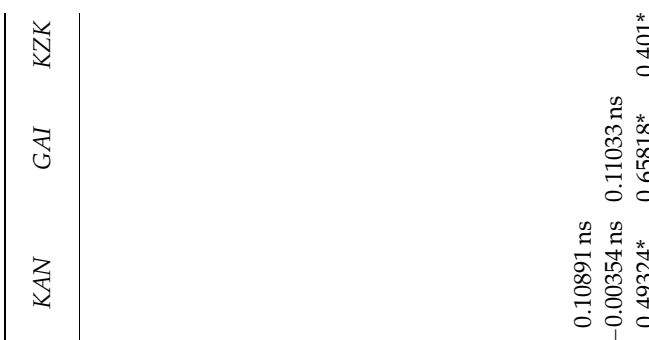

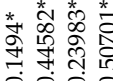

* * * * *

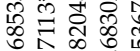

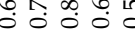

ڤั่ กิ

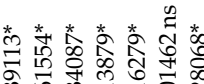

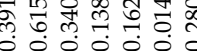

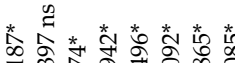

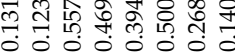

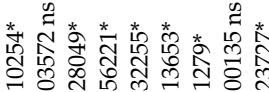

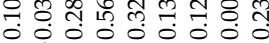

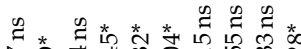

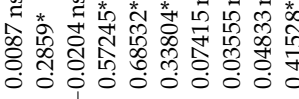

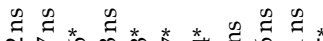

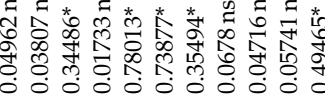
$* * * * * * * * * * * 0^{*} * *^{*} * *$

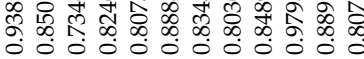
n

艺荬

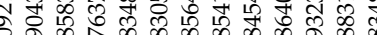

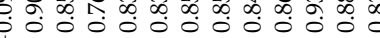

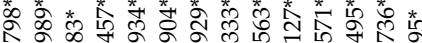

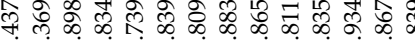
$\stackrel{2}{\Rightarrow}$

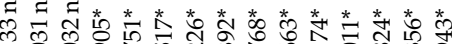

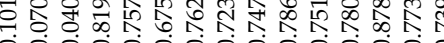

mtDNA data of the four mtDNA-phylogroups to an AMOVA revealed that $96.7 \%(P<0.00001)$ of the explained mtDNA variance was because of partitioning into these four phylogeographic groups. The associated $\phi_{\mathrm{ST}}$-value of $0.69(P<0.00001)$ indicated clearly restricted exchange of mtDNA among these four mtDNA-phylogroups.

\section{Allozyme variability}

Among the five polymorphic loci found, Pgm-2 and Es-2 were polymorphic in all populations, whereas the other three exhibited variant alleles only in one or two populations at very low frequencies (Table 3). While allele frequencies at the further two loci varied significantly across the 19 populations (Pgm-2: $G=3562.9$, d.f. $=18, \quad P<0.00001 ; \quad$ Es-2: $\quad G=3774.1, \quad$ d.f. $=18$, $P<0.00001, G$-tests), there was no such variation among the four mtDNA-phylogroups (Pgm-2: $G=2.52$, d.f. $=3$, $P>0.05$; Es-2: $G=8.08$, d.f. $=3, P>0.05$ ). Genotype frequencies did not depart significantly from HardyWeinberg expectations, both when tested separately for each population, and when tested for each of the four mtDNA-phylogroups. Levels of nuclear gene pool variability were rather similar in the single populations (see Table 3 for diversity indices), but 'central' populations showed a tendency $\left(P=0.036, \mathrm{~F}_{1,19}=5.215\right.$, covariate: sample size: $F_{1,19}=0.075, P=0.788$, ANCOVA) towards higher $H_{\mathrm{e}}$-values (mean $=3.042 \%$, range: $2.7-$ $3.4 \%$ ) than populations from the margin of the distributional range of chamois in the Eastern Alps (mean $=2.7 \%$, range: $2.1-3.2 \%$ ). The mean values of allelic richness (Rs) in 'central populations' (1.062) and 'margrinal populations' (1.060) did not differ significantly ( $P=0.31600$; one-toiled test, 1000 permutations). According to Wright's (1978) F-statistics (Table 4), only $\leqslant 5.7 \%$ of the relative variability at structural gene loci was because of distribution among populations, and Wright's (1978) hierarchical F-statistics revealed that only $\leqslant 0.45 \%$ of the relative allozymic variability was because of distribution among the four discriminated mtDNAphylogroups. Nei's (1978) genetic distances and Rogers' distances for all population pairs ranged between 0.000 0.005 and 0.005-0.092, respectively. The Wagner dendrogram (Figure 4) depicts absence of correspondence of patterns of spatial allozymic and mtDNA differentiation. This was corroborated by the Mantel test, which did not reveal a significant correspondence of the matrices of pairwise allozymic Rogers' and net nucleotide diversity values $(G=-0.395, P>0.05)$.

\section{Discussion}

\section{Phylogeographical structuring}

A geographical structuring of the mtDNA into four mtDNA-phylogroups was particularly substantiated by strongly restricted gene flow between neighbouring populations, both in the central (KIT, TAUa, TAUb vs HUN, HAG, TEN), southern (KAW vs KOR, KAW vs SAU, SAU vs KOR), and northeastern parts (HBS vs. SBS) of the study region. While these four mtDNA-phylogroups were only tentatively mirrored by the phylogenetic analysis (NJ-dendrogram, Figure 3), an AMOVA demonstrated that $96.7 \%$ of the mtDNA variance was because of partitioning into the four phylogeographic 


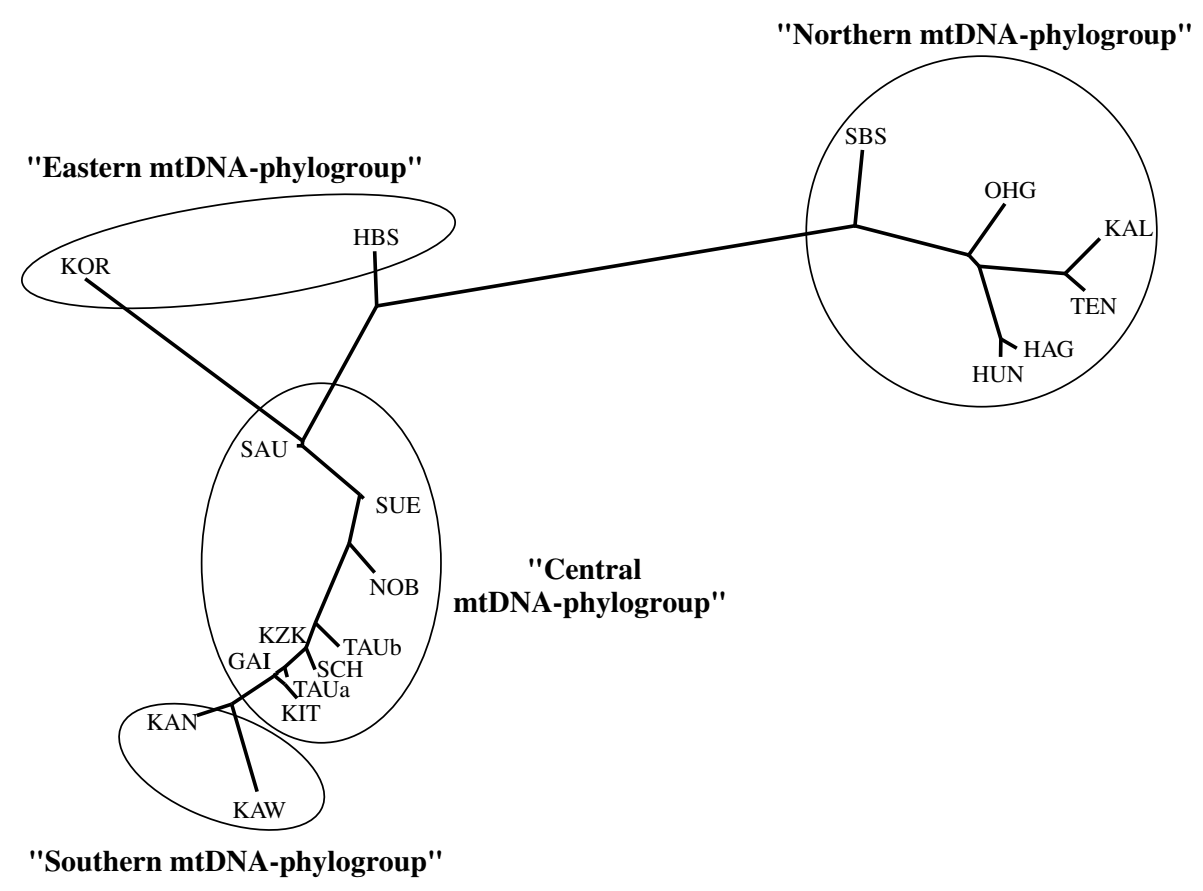

Figure 3 Neighbour joining dendrogram based on pairwise net nucleotide diversity values showing the phylogenetic relationships of mtDNA among the 19 populations. Scale indicates a net nucleotide diversity value of 0.001 .

groups, which confirms our mtDNA-phylogroups based on the spatial occurrence of haplotypes. Probably, a distinct separation of the 'southern mtDNA-phylogroup' from the 'central mtDNA-phylogroup' could not be revealed by the NJ-dendrogram, because of the relatively little evolutionary distinctiveness of the haplotypes RR2 and RR15, as well as their low frequencies in the 'Southern mtDNA-phylogroup'. Nevertheless, these two haplotypes were found exclusively in the 'Southern mtDNA-phylogroup'; moreover, one additional haplotype (RR3) only occurred in this population (Hammer et al, 1995). The 'Eastern mtDNA-phylogroup' is characterized by three haplotypes (RR6, RR7, and RR11) that did not occur in any other population, except for RR7 in the neighbouring population SAU that might have received this haplotype recently by immigrating chamois.

\section{Divergence times and postglacial colonization}

We interpret the distinct geographical structuring of the mtDNA as resulting from immigration of chamois into the Eastern Alps from different Pleistocene refugia, after the retreat of the glaciers following the late Pleistocene glacial maximum (c. 15-12 kyr BP; Van Husen, 1987). Late Pleistocene (30-12 kyr BP) fossils from north and south of the Eastern Alps (Sägesser and Krapp, 1986; Döppes, 1997) indicate that chamois roamed the ice-free low-lying country in the environs of the Alps during the late glacial maximum. Fossil bones with butchering marks indicate that chamois were hunted by Magdalénien people in ice-free parts of the lower Alps, together with other ungulates (see Galik, 1997). Considering all this, we suggest that chamois of the four mtDNA- phylogroups could have invaded the Eastern Alps from Pleistocene refugia to the north, east, south-east, and south-west of the Eastern Alps.

The estimated divergence times among these putative Pleistocene source populations, based on pairwise net nucleotide diversities, ranged between 4 kyr BP for the 'Southern-' and 'Central mtDNA-phylogroups' and $53 \mathrm{kyr}$ BP for the 'Northern-' and 'Southern mtDNAphylogroups', respectively, when calibrated on the divergence of the closest haplotypes of Pyrenean and Alpine chamois and the supposed minimum phylogenetic divergence estimate for the two species according to palaeontological data (c. $150 \mathrm{kyr}$ BP; cf. Masini and Lovari, 1988). Basing this calibration between the two chamois species on a maximum value of species divergence of $400 \mathrm{kyr} \mathrm{BP}$, resulted in estimates of population divergence ranging from 11 to $141 \mathrm{kyr}$ BP. In these calculations of population divergence, however, we disregarded those haplotypes that likely were exchanged by migrating chamois during post-Pleistocene periods (ie, haplotypes RR1, RR5 for the 'Northern mtDNAphylogroup', and RR7, RR8, RR9 for the 'Central mtDNA-phylogroup'). All population divergence estimates correspond to the late Pleistocene with periods of extensive glaciation in the Alps. Late and post-glacial lakes and river systems of melted snow and ice, as well as complex systems of moraines (for details, see Van Husen, 1987) very likely provided effective migration barriers for colonizing chamois from different Pleistocene provenances in lower Alpine regions. Nevertheless, immigration from several variably isolated source populations probably cannot fully explain the occurrence of strict mtDNA demarcations, particularly among the 'Northern-', 'Central-' and 
Table 3 Allele frequencies at polymorphic isozyme loci and indices of cross nuclear gene pool diversity of chamois per population (for acronyms see Table 1 and Figure 1 )

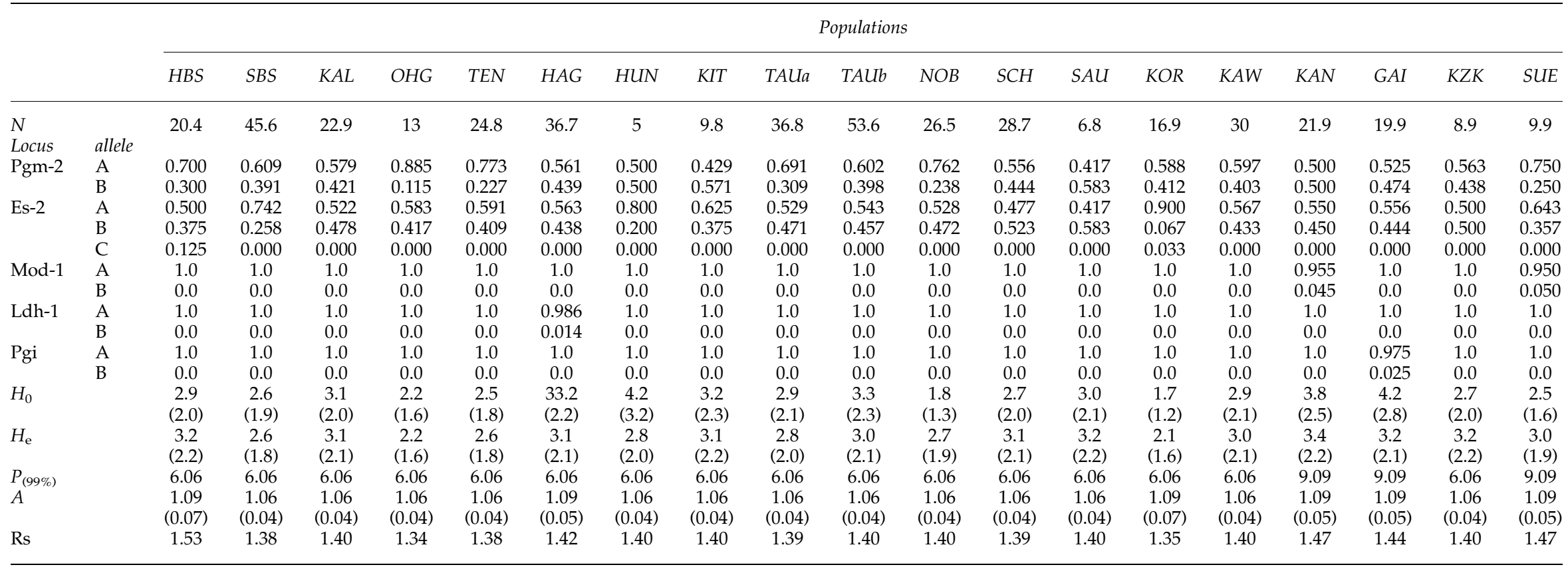

$N=$ mean sample size per locus. $H_{0}=$ observed heterozygosity $(\%), H_{\mathrm{e}}=$ expected heterozygosity $(\%), P_{(99 \%)}=$ rate of polymorphism $(99 \%$ criterion), $A=$ mean number of alleles per locus, based on all 33 loci scored. Rs=allelic richness (mean over all five polymorphic loci). 
Table 4 Relative genetic differentiation among the populations. Summary of Wright's (1978) F-statistics at all allozyme loci

\begin{tabular}{lrrr}
\hline Locus & \multicolumn{1}{c}{$F_{I S}$} & $F_{I T}$ & $F_{S T}$ \\
\hline Pgm-2 & 0.036 & 0.093 & 0.060 \\
Es-2 & -0.111 & -0.049 & 0.056 \\
Me-1 & -0.050 & -0.005 & 0.043 \\
Ldh-1 & -0.014 & -0.001 & 0.013 \\
Pgi & -0.026 & -0.001 & 0.024 \\
Mean & -0.039 & 0.020 & 0.057 \\
\hline
\end{tabular}

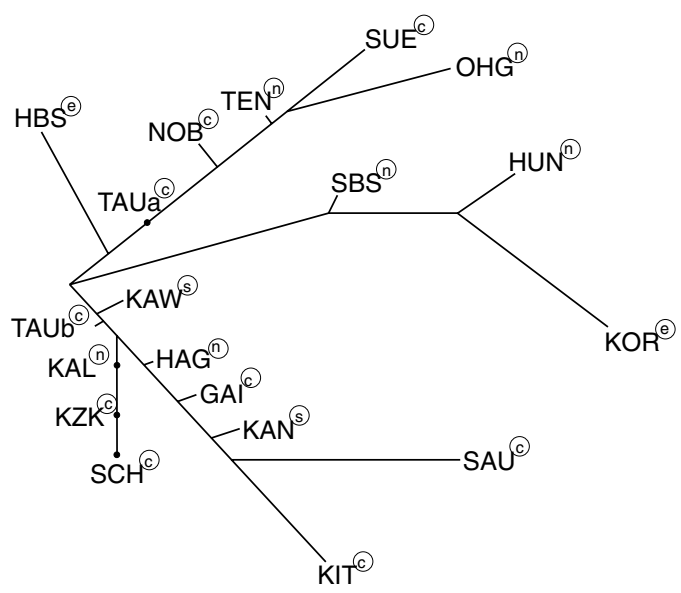

Figure 4 Wagner dendrogram based on Rogers' 1978 distances calculated from 33 allozyme loci. Upper case letters with acronyms allocate single populations to one of the four distinct mtDNAphylogroups found presently (see Figure 1). Total tree length $=0.224$. Cophenetic correlation coefficient $=0.934$.

'Eastern mtDNA-phylogroups'. These demarcations indicate that diffusion of mtDNA gene pools has more or less ceased, once ice-free mountain massifs have been colonized. Rapid colonization of the deglaciated mountain ranges might have led to quick reductions of habitat capacities and subsequently to changes from $\mathrm{r}$ - to $\mathrm{K}$ strategy in late-glacial Alpine chamois populations, as was observed in chamois introduced to New Zealand (Bauer, 1982). Under the K-strategy, chamois would develop more stable populations with a lower tendency towards expansion. Among female chamois from a population in the Western Alps, more than 90\% were philopatric, while males had a higher tendency to dispersal (Loison et al, 1999).

\section{Discordance of spatial patterns of mtDNA and nuclear DNA}

The striking geographical structuring of the maternal genome was not reflected by nuclear DNA, as assessed by allelic variation at five allozyme loci in 443 chamois from the Eastern Alps. While phylogenetically related mtDNA haplotypes could be arranged into four mtDNAphylogroups, allele frequencies at polymorphic allozyme loci did not result in a corresponding pattern of geographic differentiation. This was particularly evidenced by the insignificant result of the Mantel test
( $G=-0.179, \quad P>0.05)$ for concordance of values of pairwise net nucleotide diversity and allozyme Rogers' distances for the four phylogenetic mtDNA-groups. Moreover, overall genetic differentiation at structural gene loci was low among the regional chamois populations. Similarly, low allozymic differentiation among local or regional populations were also found, at least in parts, in other studies of Alpine chamois (R. r. rupicapra) from the Eastern and Western Alps, the Black Forest and Vosges (Miller and Hartl, 1986; Miller, 1989; Pemberton et al, 1989) as well as in chamois from the Cantabrian mountains (Peréz-Barbería et al, 1996). And according to Nascetti et al (1985), the two subspecies of Pyrenean chamois from the Pyrenees (R. p. pyrenaica) and the Apennine mountains in Italy ( $R$. $p$. ornata) have only marginally higher values of allozymic divergence than those that we found in the Eastern Alps.

In the present study, allozymic gene pool divergence did not increase with geographic distance. Hence, the spatial pattern of allozymes cannot be explained by an isolation-by-distance model. The low overall fixation index $\left(\mathrm{F}_{\mathrm{ST}}=0.057\right)$ indicates sufficient gene flow among regional populations, and the hierarchical F-statistics indicated that most of the presently found relative allozymic variability was partitioned among chamois within local populations rather than among the four mtDNA-phylogroups. On the whole, topographic and ecological characteristics of the Alpine environment, such as low-lying valleys, wide basins with rivers or lakes, urban areas, highways, extended glaciers or large woodlands do not appear to cause significant substructuring of the nuclear genome in chamois from the Eastern Alps.

The rather approximately panmictic network of nuclear gene pools of chamois from the Eastern Alps, contrary to the clear segregation of mtDNA into four regional mtDNA-phylogroups with distinct demarcations, can be interpreted as resulting either from sexspecific migration and gene exchange particularly mediated by bucks, or by balanced polymorphism at the Pgm-2 and Es-2 loci, which contribute most to the overall allozymic diversity. The first hypothesis is substantiated by telemetric findings in chamois from the Western Alps, which indicate philopatry of female chamois and a tendency to dispersal in bucks (Loison et al, 1999). Such sex-specific dispersal was also envisaged to explain higher levels of substructuring of mitochondrial than nuclear gene pools in bighorn sheep (Ovis canadensis) from southwestern USA and Mexico (Ramey, 1995), wolverines (Gulo gulo) from the Northwest Territories, Canada (Wilson et al, 2000), and whitetailed deer (Odocoileus virginianus) from the coastal plain in Georgia and South Carolina, USA (Purdue et al, 2000). As regards balanced polymorphism, overdominance has been suggested to occur at diverse allozymic loci of various ungulate species. On the Isle of Rum (Scotland), red deer calves (Cervus elaphus) with heterozygous genotypes at the Idh-2 locus had significantly higher chances of survival within their first and second years of life (Pemberton et al, 1988), and among Soay sheep of St Kilda (Scotland), individuals with heterozygous genotypes at the Ada-locus showed best survival during extreme population crashes (Gulland et al, 1993). Levels of allozymic differentiation among various chamois populations studied earlier in the Eastern and Western 
Alps (Miller and Hartl, 1986; Miller, 1989; Pemberton et al, 1989) were similarly low to the values found in this study. However, these low values of population differentiation were not, in general, because of stable allele frequencies at the Pgm-2 and Es-2 loci. This might indicate that a generally high level of gene flow among chamois populations (see also Peréz-Barbería et al (1996) for Cantabrian chamois) thus exists, rather than an overdominance effect at several of the studied loci. In this study, we did not find significant deviations of genotype frequencies from the Hardy-Weinberg equilibrium at the Pgm-2 and Es-2 loci in any of the populations. However, with the relatively small sample sizes of regional samples, slightly increased numbers of heterozygotes are likely not detectable. In the combined sample of all 443 chamois from the populations, we found a significant ( $P=0.013$, exact Fisher's test) deviation of Hardy-Weinberg expectations owing to increased numbers of heterozygotes at the Es-2 locus but significantly ( $P=0.001$, exact Fisher's test) less heterozygotes at the Pgm-2 locus than expected. While the deficit of heterozygotes at the Pgm-2 locus can be explained by a 'Wahlund effect', the preponderance of Es-2 heterozygotes, in spite of an expected 'Wahlund effect', may indeed be because of overdominance. Disregarding the Es-2 locus for calculations of genetic distances among regional populations, however, resulted in essentially the same low levels of genetic differentiation of the nuclear gene pools (Nei's (1978) $D=0.000-0.006$ and Rogers' distances $=0.001-0.083$ ), suggesting substantial gene flow in the nuclear genome. In conclusion, chamois from the Eastern Alps show a distinct phylogeographic structuring in the mtDNA, but this was not paralleled by the allozyme markers. The low level of genetic differentiation as revealed by the allozyme markers could result from stabilizing selection at one locus (Es2) and high gene flow mediated by male dispersal.

\section{Acknowledgements}

We thank the following persons for organizing sampling or providing samples: J Schöchel, A Pacher-Theinburg, F Osterbauer from den Landesveterinärdirektion Salzburg; J Kristan, secretary of the Salzburger Jägerschaft; W Kulterer, secretary of the Kärntner Jägerschaft; H Gufler (Meran, Italy), R Bögel, from the Nationalpark Berchtesgaden (Germany); A Bidovec (University Ljubljana, Slovenia); A Neuhold (Deutschlandsberg); K Hilscher (Scheibbs); and all hunters for shooting and collecting organ samples. A Haiden (Vienna) provided extensive laboratory assistance. Financial support was granted by the 'Abteilung Kultur und Wissenschaft des Amtes der Niederösterreichischen Landesregierung'.

\section{References}

Anderson S, De Brouijn MHL, Coulson AR, Eperon IC, Sanger F, Young IG (1982). Complete sequence of bovine mitochondrial DNA. J Mol Biol 156: 683-717.

Bandelt HJ, Dress AWM (1992). A canonical decomposition theory for metrics on a finite set. Adv Math 92: 47-50.

Bauer JJ (1982). Untersuchungen zur Dynamik von Stabilen und Kolonisierenden Gemsenpopulationen (Rupicapra rupicapra) in Neuseeland. Dissertation, Institut für Wildbiologie und Jagdwirtschaft der Univ. für Bodenkultur, Wien.
Döppes D (1997). Die Jungpleistozäne Säugetierfauna der Gudenushöhle (Niederösterreich). Wiss Mitt Niederösterr Landesmuseums 10: 17-32.

Excoffier L, Smouse P, Quattro JM (1992). Analysis of molecular variance inferred from metric distances among DNA haplotypes: application to human mitochondrial DNA restriction data. Genetics 131: 479-491.

Felsenstein J (1993). PHYLIP - Phylogeny Inference Package, version $3.5 \mathrm{c}$. Department of Genetics, University of Washington, Seattle.

Galik A (1997). Die Ungulata aus der Schusterlucke im Kremstal (Waldviertel, Niederösterreich). Wiss Mitt Niederösterr Landesmuseums 10: 83-103.

Goudet J (2001). Fstat, a program to estimate and test gene diversities and fixation indices (version 2.9.3). Available at http://www.unil.ch/softwares/fstat.html.

Grillitsch M, Hartl GB, Suchentrunk F, Willing R (1992). Allozyme evolution and the molecular clock in the Lagomorpha. Acta Theriol 37: 1-13.

Gulland FMD, Albon SD, Pemberton JM, Moorcroft P, CluttonBrock TH (1993). Parasite-associated polymorphism in a cyclic ungulate population. Proc of the $R$ Soc of London B 254: 7-13.

Hammer S, Nadlinger K, Hartl GB (1995). Mitochondrial DNA differentiation in chamois (genus Rupicapra): implications for taxonomy, conservation, and management. Acta Theriol (Suppl. 3): 145-155.

Harris H, Hopkinson DA (1976). Handbook of Enzyme electrophoresis in Human Genetics. North Holland: Amsterdam.

Hartl GB, Höger H (1986). Biochemical variation in purebred and crossbred strains of domestic rabbits (Oryctolagus cuniculus). Genet. Res. Cambridge 48: 27-34.

Hartl GB, Suchentrunk F, Nadlinger K, Willing R (1993) An integrative analysis of genetic differentiation in the brown hare Lepus europaeus based on morphology, allozymes, and mitochondrial DNA. Acta Theriol, 38 (Suppl 2): 33-57.

Huson DH (1998). SplitsTree: analyzing and visualizing evolutionary data. Bioinformatics 14: 68-73. Available at http:// bibiserv.techfak.uni-bielefeld.de/splits/.

Lang G (1994). Quartäre Vegetationsgeschichte Europas. Guatav Fischer Verlag: Jena.

Loison A, Jullien J-M, Menaut P (1999). Subpopulation structure and dispersal in two populations of chamois. J Mammal 80: 620-632.

Lovari S (1987). Evolutionary aspects of the biology of chamois, Rupicapra spp. (Bovidae, Caprinae). In: Soma H (ed) The biology and management of Capricornis and related mountain antelopes, Croom-Helm: London. pp 51-61.

Mantel N (1967). The detection of disease clustering and a generalized regression approach. Cancer Res 27: 209-220.

Masini F, Lovari S (1988). Systematics, phylogenetic relationships and dispersal of the chamois (Rupicapra spp.). Quat Res 30: 339-349.

McElroy D, Moran P, Bermingham E, Kornfield I (1992). REAP: an integrated environment for the manipulation and phylogenetic analysis of restriction data. J Hered 83: 157-158.

Miller C (1989). Genetische Differenzierung von Gamskolonien. In: Linn S (ed) CIC-Gamswildsymposium, Ljubljana, 25/26 October 1988, pp. 71-86.

Miller C, Hartl GB (1986). Genetic variation in two alpine populations of chamois (Rupicapra rupicapra L.). Z Säugetierk 51: 114-121.

Nascetti G, Lovari S, Lanfranchi P, Berducou C, Mattiucci S, Rossi L et al (1985). Revision of Rupicapra genus III. Electrophoretic studies demonstrating species distinction of chamois populations of the Alps from those of the Apennines and Pyrenees. In: Lovari S (ed) Biology and Management of Mountain Ungulates, Croom-Helm: London. pp. 57-62. 
Nei M (1978). Estimation of average heterozygosity and genetic distance from a small number of individuals. Genetics 89: 583-590.

Nei M, Li MH (1979) Mathematical model for studying genetic variation in terms of restriction endonucleases. Proc Nat Acad Sci USA 76: 5269-5273.

Nei M (1987). Molecular Evolutionary Genetics. Columbia University Press: New York.

Peréz-Barbería FJ, Machodrom A, Fernández J, Nores C (1986). Genetic variability in Cantabrian chamois (Rupicapra pyrenaica parva Cabrera, 1910). Z Säugetierk 61: 276-284.

Pemberton JM, Albon SD, Guinness FE, Clutton-Brock TH, Berry RJ (1988). Genetic variation and juvenile survival in red deer. Evolution 42: 921-934.

Pemberton JM, King PW, Lovari S, Bauchau V (1989). Genetic variation in the Alpine chamois with special reference to the subspecies Rupicapra rupicapra carthusiana. Z Säugetierk 54: 243.

Purdue JR, Smith MH, Patton JC (2000). Female philopatry and extreme spatial genetic heterogeneity in white-tailed deer. $J$ Mammal 81: 179-185

Ramey RR (1995). Mitochondrial DNA variation, population structure, and evolution of mountain sheep in the southwestern United States and Mexico. Mol Ecol 4: 429-439.

Rice WS (1989). Analyzing tables of statistical tests. Evolution 43: 223-225.

Rossi L, Meneguz PG, De Martin P, Rodolfi M (1995). The epizootiology of sarcoptic mange in chamois Rupicapra rupicapra, from the Italian Eastern Alps. Parassitologia 37: 233-240.

Rothe GM (1994). Electrophoresis of Enzymes. Laboratory Methods. Springer LAB Manual. Springer: Berlin.
Rousset F (1997). Genetic differentiation and estimation of gene flow from f-statistics under isolation by distance. Genetics 145: 1219-1228.

Sägesser H and Krapp F (1986). Rupicapra rupicapra (Linnaeus, 1758), Gämse. In: Niethammer J and Krapp F (eds), Handbuch der Säugetiere Europas, Aula-Verlag: Wiesbaden. pp 316-348.

Schneider St, Kueffer J-M, Roessli D, Excoffier L. (1996) ARLEQUIN 1.1: software package for population genetics. Department of Anthropology, Geneva.

Shackleton DM (ed) and the IUCN/SSC Caprinae specialist group (1997). Wild sheep and goats and their relatives. Status Survey and Conservation Action Plan for Caprinae. IUCN: Gland, Switzerland and Cambridge.

Swofford DL, Selander RB (1989). BIOSYS-1. A computer program for the analysis of allelic variation in population genetics and biochemical systematics. Release 1.7. Users manual. Illinois Natural History Survey, Champaign, IL.

Taberlet P, Fumagalli L, Wust-Saucy A-G, Cosson J-F (1998). Comparative phylogeography and postglacial colonization routes in Europe. Mol Ecol 7: 453-464.

Van Husen D (1987) Die Ostalpen und ihr Vorland in der letzten Eiszeit (Würm) - glacier map. Geologische Bundesanstalt: Wien.

Wilson GM, Van Den Bussche RA, Kennedy PK, Gunn A, Poole K (2000). Genetic variability of wolverines (Gulo gulo) from the Northwest Territories, Canada: conservation implications. J Mammal 81: 186-196

Wright S (1978). Evolution and the genetics of populations. Vol. 4 Variability in and among natural populations. University of Chicago Press: Chicago. 